\title{
Análise dos aspectos motivacionais de estudantes em uma disciplina eletiva de Astronomia
}

\author{
Bruno de Andrade Martins ${ }^{1}$ \\ Doutorando em Ensino de Ciências \\ Universidade Federal de Mato Grosso do Sul \\ Maria Celina Piazza Recena ${ }^{1}$ \\ Universidade Federal de Mato Grosso do Sul \\ Campo Grande - MS
}

\section{Resumo}

Este artigo relata uma pesquisa cujo objetivo foi estudar os aspectos que conduziram à motivação para a participação em uma disciplina de Astronomia por parte do público-alvo (estudantes do ensino médio) em um espaço escolar de ensino. Para o estudo da motivação, usamos como referencial teórico a Teoria da Autodeterminação, que se dedica a estudar aspectos relacionados com a motivação humana. Para nortear a análise, fundamentamo-nos no referencial metodológico qualitativo da Análise Textual Discursiva, que busca a compreensão das novas interpretações a partir dos dados da pesquisa. Como fonte de dados, usamos um questionário respondido pelos participantes no término da eletiva. Os resultados apontam que a Astronomia pode ser considerada potencialmente motivadora para casos semelhantes ao aqui estudado, pois foram diagnosticados, em todos os estudantes participantes, indícios de motivação intrínseca. Os resultados da pesquisa também apontam que a Astronomia deve ser trabalhada de alguma forma na educação básica, pois apresentou estudantes autônomos, competentes e comprometidos com as atividades desenvolvidas.

Palavras-chave: Educação em Astronomia; Ambientes Escolares; Teoria da Autodeterminação.

\footnotetext{
${ }^{+}$Analysis of motivational aspects of students in an elective Astronomy discipline

* Recebido: janeiro de 2020. Aceito: julho de 2020.

${ }^{1}$ E-mails: martinsfisica@gmail.com; mcrecena@yahoo.com.br
} 


\begin{abstract}
The article reports a research where the objective was to study the aspects that led to the motivation for the participation in an Astronomy discipline by the target audience (high school students) in a school. For the study on motivation it was used as a theoretical framework in which they approached the subject of self-determination theory dedicating themselves to the study of aspects related to human motivation. To guide the analysis we are based on the qualitative methodological framework of discursive textual analysis, seeking to understand the new interpretations from the research data. As a data source, a questionnaire was used, which was answered by the elective participants, thus concluding this work. The results show that astronomy can be considered potentially motivating for cases similar to studied here as they have been diagnosed in all participating students, intrinsic motivation of evidence. The results of the research indicate that Astronomy must be worked on in basic education, because they presented autonomous students, competent and committed to the activities developed.
\end{abstract}

Keywords: Astronomy Education; School Environments; SelfDetermination Theory.

\title{
I. Introdução
}

A Astronomia, ciência que se dedica a estudar os corpos celestes e o Universo como um todo, desde a sua formação, foi uma das primeiras ciências examinadas pelo homem. Sua prática é registrada nos mais antigos documentos escritos, em monumentos paleolíticos e em pinturas rupestres. A Astronomia possui um papel importante para a compreensão da origem da vida na Terra, buscando responder questões como, por exemplo: de onde viemos e para onde vamos. Assim, mostra-se importante o homem buscar compreender mais essa ciência, que pode ajudar a explicar a nossa origem.

$\mathrm{O}$ avanço tecnológico e estudos científicos da Astronomia contribuem para o deslumbramento do público diante dessa ciência, pois vemos a utilização de tecnologias em nosso cotidiano como, por exemplo: ao usarmos o GPS, na compreensão das estações do ano, das fases da Lua, do dia e da noite, na contagem do tempo, na construção de calendários, nas influências sobre as marés, nas orientações para navegações, nos satélites, etc. Deste modo, observa-se que a Astronomia, e os aparatos tecnológicos dela oriundos, encontram-se incorporados ao dia-a-dia de cada indivíduo, seja explícita ou implicitamente.

A Astronomia, apesar de ter os seus conteúdos sugeridos pelos documentos oficias, como por exemplo, os Parâmetros Curriculares Nacionais (BRASIL, 1999, 2002) (PCN), a 
Base Nacional Comum Curricular (BNCC), apresenta-se concepções espontâneas acerca do tema por parte da população. Um dos fatores que contribuem para isso é a falta de divulgação e de atividades relacionadas a essa ciência em escolas e para o público em geral, assim como aponta Langhi e Nardi (2007). Sem o devido estudo nas escolas, o indivíduo poderá permanecer com esses conceitos equivocados por toda a vida. Além disso, podemos transmitilos adiante, o que contribui para o crescimento das concepções acerca desse tema. Langhi (2009) apresenta uma das prováveis causas que justificam a não inclusão da Astronomia nas escolas:

\begin{abstract}
Nem mesmo o professor brasileiro do ensino fundamental e médio, na maioria dos casos, aprende conteúdos de astronomia durante a sua formação na faculdade. Como consequência, os professores, em geral, optam por duas alternativas: preferem não ensinar astronomia ou buscam outras fontes de informações. Porém, há carência de fontes seguras sobre astronomia, pois até mesmo livros didáticos apresentam erros conceituais. A mídia é escassa em documentários sobre este tema, e muitas vezes prefere exagerar no sensacionalismo em noticias que envolvem assuntos sobre o espaço sideral. Não temos uma quantidade suficiente de planetários, observatórios, museus de ciências e associações de astrônomos amadores que poderiam servir de eficiente apoio ao ensino de astronomia nas escolas (LANGHI, 2009, p. 11).
\end{abstract}

Uma pesquisa realizada em turmas do curso de Licenciatura do Instituto de Física da Universidade de São Paulo (IFUSP) por Alves e Zanetic (2008), aponta que 67,3\% dos estudantes participantes alegaram nunca ter observado o céu noturno utilizando algum instrumento óptico. Contudo, 90\% acreditam ser possível observar algum planeta do nosso sistema solar a olho nu, mas não sabem afirmar ao certo qual.

Outra pesquisa que aponta para falta de atividades relacionadas a Astronomia em um espaço formal de ensino, é a de Alves e Jafelice (2005) onde apresenta-se um levantamento que identifica quantos estudantes da rede pública estadual de ensino da cidade de Natal (RN) já realizaram algum tipo de observação astronômica. A pesquisa mostrou que $79 \%$ dos estudantes entrevistados nunca observaram o céu noturno utilizando algum instrumento óptico como um telescópio, um binóculo ou uma luneta por falta de oportunidades.

Essas pesquisas apresentadas, entre outras sobre Educação em Astronomia, mostram a existência de um desconhecimento da população em geral sobre esse tema, principalmente no que diz respeito à Astronomia Observacional, a qual é apresentada como um dos sete principais temas em Astronomia, explorados por diversos autores, segundo um levantamento realizado por Langhi e Nardi (2010). Os outros seis temas são: forma da Terra, fases da Lua, estações do ano, campo gravitacional, dia e noite, órbita terrestre. Segundo a análise dos autores, essas concepções poderiam ser minimizadas se fossem, de algum modo, abordadas dentro das disciplinas do currículo escolar, como Física, Química, Geografia, entre outras ou, ainda, ter a disciplina de Astronomia contemplada no currículo da educação básica. 
Langhi (2009) apresenta um levantamento bibliográfico apontando que muitos indivíduos, entre professores e alunos, apresentam-se mais incentivados e motivados a aprender ao observar imagens reais do Universo por meio de um telescópio, uma vez que essa é uma experiência nunca realizada por eles. Segundo o mesmo autor, é reconhecido que a observação direta de corpos celestes por meio de telescópios, independentemente do objeto observado, pode fazer com que uma pessoa incorpore uma experiência astronômica real.

Essa atividade observacional pode ser incluída no contexto da educação básica, por meio de parcerias com clubes de ciências, Universidades, observatórios ou, até mesmo, obter os telescópios com recursos governamentais para a escola. Essa atividade é importante, pois mostra ao estudante o seu e o nosso lugar no cosmo, pois o ajuda a colocar em prática os seus conhecimentos adquiridos em sala de aula. Atividades com o uso de telescópios podem despertar o educando para o aprendizado, favorecendo sua curiosidade natural, o que se caracteriza como um dos objetivos para a educação segundo os PCNs (BRASIL, 1999, 2002).

A formação deficiente do professor para o ensino da Astronomia remete a algumas consequências com relação à atuação docente em sala de aula, uma vez que a educação formal não lhe garantiu uma abordagem desses saberes disciplinares (LANGHI, 2009). Algumas destas consequências são: a dificuldade em ensinar e aprender conteúdos que envolvem o estudo da Astronomia; a propagação de erros conceituais, concepções alternativas, mitos; entre outros (LANGHI; NARDI, 2007). Por isso, destaca-se a importância da atuação contextualizada das instituições (universidade e escolas) para o ensino e divulgação dessa ciência. Porém, temos que reconhecer que tais ações não podem ser realizadas a partir do senso comum e que há a necessidade de se levar em conta o que pesquisas sobre o tema têm mostrado.

Em 2009 foi comemorado o ano internacional da Astronomia (AYA). Como forma de divulgar essa ciência, algumas universidades, como, a Universidade Federal de Mato Grosso do Sul (UFMS), realizaram atividades direcionadas a essa. Essas atividades foram sugeridas pela União Internacional da Astronomia, com o objetivo de:

$>$ Difundir na sociedade uma mentalidade científica.

$>$ Promover acesso a novos conhecimentos e experiências observacionais.

$>$ Promover comunidades astronômicas em países em desenvolvimento.

$>$ Promover e melhorar o ensino formal e informal da ciência.

$>$ Fornecer uma imagem moderna da ciência e do cientista.

$>$ Criar novas redes e fortalecer as já existentes.

$>$ Melhorar a inclusão social na ciência, promovendo uma distribuição mais equilibrada entre os cientistas provenientes de camadas mais pobres, de mulheres e minorias raciais e sexuais.

Tais objetivos foram implantados pelo próprio comitê do evento, com a intensão de uniformizar as atividades e divulgação da Astronomia. $\mathrm{O}$ evento não foi designado apenas a ser realizado ao longo do ano de 2009 , mas através da herança desta celebração, cria-se canais 
de comunicação, programas educacionais a longo prazo e engajamento de jovens na carreira científica.

Mesmo com a sugestão dos documentos oficias desde o ensino fundamental até o médio, como, por exemplo, os Parâmetros Curriculares Nacionais (PCN) (BRASIL, 1999, 2002) e as Orientações Curriculares Nacionais do Ensino Médio (OCNEM) (BRASIL, 2006), trabalhos como o de Langhi e Nardi (2010) apontam que a Astronomia não está sendo incluída no currículo escolar como sugerem os documentos oficiais citados. Mais recentemente após a sua reformulação, a Base Nacional Comum curricular (Brasil, 2017) também sugere a implementação da Astronomia desde o ensino fundamental até o ensino médio.

Após um levantamento realizado no portal do ministério da educação (MEC), verifica-se que existem poucas universidades no país que oferecem cursos de graduação, mestrado ou doutorado em Astronomia ou mesmo alguma disciplina relacionada. Assim, constata-se a falta de preparação dos professores (da educação básica) frente ao tema, o que colabora para a não divulgação dessa ciência nas escolas, pois, segundo Langhi (2004) esses profissionais não se sentem seguros em ministrá-lo em sala de aula, devido ao pouco conhecimento que possuem da referida área.

Para os PCN (BRASIL, 1999 e 2002), a Astronomia deve ser trabalhada desde o ensino fundamental em várias disciplinas como Geografia, História, Ciências, entre outras, tendo a sua continuação, no ensino médio, nas disciplinas já citadas e na Física, Biologia e Química. Assim, essa mostra seu caráter interdisciplinar, relacionando várias áreas em uma única ciência.

A inclusão da Astronomia deve ocorrer nos ensinos fundamental e médio. No primeiro, devem-se trabalhar conteúdos básicos que estão inseridos no eixo temático "Terra e Universo". Para isso, os professores devem utilizar atividades simples e práticas como a construção de gnômons, relógios de Sol, observação da Lua (BRASIL, 1999), etc. Na BNCC (BRASIL, 2017), a Astronomia é citada e sugerida nas habilidades especificas II para o ensino médio. Para o ensino fundamental, é orientado o seu conteúdo nas unidades temáticas, objetivos de conhecimentos e habilidades (Terra e Universo). É sugerido que esses conteúdos, sejam contemplados em disciplinas como Geografia, Ciências e Ciências da Natureza, sendo cada nível um complemento dos anos anteriores.

Constatando essa importância da Astronomia para a educação básica, realçada pelos documentos oficias, a pesquisa buscou uma ação para aproximar os estudantes de uma escola estadual de Campo Grande, MS, dessa ciência que nos diz muito de "nós mesmos". Busca-se contemplar conceitos básicos, como as fases da Lua, estações do ano, Sistema Solar, Astronomia observacional, entre outros temas citados por Langhi e Nardi (2010), Bretones (1999), pelos PCN (BRASIL, 1999 e 2002) e pela BNCC (BRASIL, 2017). 


\section{I.1 As pesquisas e a motivação para o ensino da Astronomia}

Embora o discurso comum da literatura acadêmica das pesquisas sobre Educação em Astronomia seja o de que essa ciência é motivadora, encontrou-se apenas um trabalho com uma fundamentação teórica e um estudo específicos sobre a motivação no estudo da Astronomia. Trabalhos como Langhi (2004), Langhi (2009), Kantor (2001), entre outros, afirmam que a Astronomia é motivadora, mas não se baseiam em nenhum referencial teórico sobre o assunto para demonstrar tal afirmação.

O trabalho de Langhi e Martins (2018) foi o único encontrado que faz uma análise dos aspectos motivacionais em uma atividade astronômica, porém essa pesquisa foi realizada em um espaço não formal de ensino. Essa pesquisa mostrou, por meio de um referencial teórico sobre o tema, que a Astronomia realmente pode ser considerada potencialmente motivadora, uma vez que os participantes da atividade desenvolvida apresentaram possuir indícios significativos de motivação, tais como autonomia, competência, pertencimento, entre outros aspectos relacionados à motivação intrínseca.

Diante da falta de trabalhos que façam a correlação Astronomia/motivação, vê-se a necessidade de realizar uma pesquisa para mostrar se essa ciência pode ou não ser considerada potencialmente motivadora em um espaço formal de ensino, guiado por um referencial teórico adequado sobre aspectos motivacionais.

Como a Astronomia é uma ciência que abrange vários temas, não é possível verificar, nessa pesquisa, se em todas as atividades, seja em qualquer ambiente de ensino, os participantes apresentarão indícios de motivação. Assim, propõe-se, aqui, analisar os aspectos motivacionais encontrados nos estudantes de uma disciplina da parte diversificada chamada "Conceitos básicos de Astronomia e a construção de materiais didáticos", desenvolvida em uma escola pública de tempo integral em Campo Grande, MS. Esse estudo foi realizado durante o primeiro semestre de 2018 em uma disciplina denominada "eletiva" que faz parte do currículo escolar de um novo modelo de escola implantado no referido estado, chamada "Escola da Autoria" (ICE, 2015).

Uma disciplina eletiva é uma disciplina temática da parte diversificada do currículo, oferecida semestralmente, proposta pelos professores e/ou pelos estudantes e objetiva diversificar, aprofundar e/ou enriquecer os conteúdos e temas trabalhados nas disciplinas da Base Nacional Comum do currículo (ICE, 2015).

Essas Eletivas são escolhidas pelos estudantes, ou seja, eles escolhem a que desejam participar (obedecendo ao número de vagas ofertadas) a partir do interesse demonstrado na apresentação dos temas pelos professores. Essa diversificação se aplica também ao aspecto metodológico utilizado pelo docente, pois, nesse modelo de ensino, há a oportunidade de aplicar uma grande variedade de opções e recursos didáticos (ICE, 2015).

Mediante tal contexto, a questão central dessa pesquisa é: a partir dos aspectos motivacionais (intrínsecos e extrínsecos) encontrados nos estudantes de uma eletiva de 
Astronomia realizada em um espaço formal de ensino, pode-se considerar que essa ciência foi potencialmente motivadora para a participação dos estudantes nessa disciplina?

\section{Referencial teórico}

Como essa pesquisa tem por objetivo principal estudar os aspectos motivacionais encontrados nos estudantes de uma disciplina eletiva de Astronomia, foi realizada uma investigação para estudar qual seria o melhor referencial teórico sobre motivação que poderia ser adotado para tal. Após um levantamento bibliográfico das teorias sobre motivação, constatamos que a teoria proposta por Deci e Ryan (1985) é a mais próxima encontrada capaz de atender aos propósitos principal e específico desse trabalho.

Tal teoria analisa o que pode levar um indivíduo a se sentir motivado em participar de alguma atividade em qualquer ambiente. Para tal, leva-se em consideração as motivações extrínsecas e intrínsecas de um indivíduo, o seu comportamento frente a algo que possa incentivá-lo e estuda o seu desempenho motivacional na atividade desenvolvida. Para compreender melhor a teoria proposta por Deci e Ryan (1985), é necessário fazer aqui um estudo breve sobre a motivação, suas aplicações, definição, bem como a motivação extrínseca e a intrínseca.

Para Cavenaghi e Bzuneck (2009), "o termo motivação tem sua origem no verbo latino movere, cujo tempo supino motum e o substantivo motivum do latino tardio, deram origem ao termo aproximado motivo". Vários psicólogos e estudiosos da área, apesar de conceituarem o termo motivação, concordam que defini-lo é muito difícil, pois se trata de algo interno ao ser humano.

Segundo Martins (2014) e Langhi e Martins (2018), o estudo da motivação consiste em analisar, estudar os fatores que levam os indivíduos a terem determinadas ações ou atitude dirigidas para que, no futuro, possam alcançar determinados objetivos, tarefas, etc. Já para Bzuneck (2004), a motivação é um conjunto de fatores ou processo que leva, instiga ou provoca uma escolha, iniciando um comportamento que está direcionado a um objeto. Para Cavenaghi (2009), a motivação é um processo pelo qual a atividade direcionada a uma meta é instigada e sustentada.

A motivação possibilita a um indivíduo várias opções, oferecendo a ele recursos ideais, que tornarão possíveis suas escolhas autênticas, promovendo resultados satisfatórios, uma vez que ela aumenta o nível de interesse e compreensão, os quais geram aprendizagem.

Deci e Ryan (1985) foram uns dos primeiros pesquisadores a estudar os efeitos da motivação no comportamento humano e suas aplicações no processo de ensino-aprendizagem. Nessa obra, encontra-se uma macroteoria da motivação que os autores classificam como Teoria da Autodeterminação (TAD). Segundo eles, esse estudo possui a finalidade de compreender a personalidade da motivação humana, tanto intrínseca quanto extrinsecamente, pois analisa todos os aspectos favoráveis ou não para que esse estímulo possa ocorrer. Assim, essa vertente é a que mais se aproxima dos objetivos desta pesquisa. 
Para Reeve, Deci e Ryan (2004) a autodeterminação é uma tendência humana inata e está relacionada à motivação intrínseca. Assim, os indivíduos realizam atividades de forma natural sem pressão externa sobre elas, estimulando as suas capacidades já existentes.

Com o objetivo de responder à questão central desta pesquisa, é necessário buscar aspectos potencialmente motivacionais presentes nos participantes da atividade realizada. Assim, procuramos contemplar uma teoria que abordasse particularidades relacionadas à motivação (intrínseca e extrínseca) e como elas poderiam influenciar o comportamento humano, principalmente em uma determinada atividade.

Portanto, observamos que a perspectiva da TAD, descrita também por Ryan e Deci (2002), apresentava subteorias que iriam ao encontro do problema de questão citado. As quatro subteorias são: Teoria das Necessidades Básicas, Teoria da Avaliação Cognitiva, Teoria da Orientação de Causalidade e Teoria da Integração Organísmica. Segundo esses autores, as três necessidades básicas psicológicas inatas, subjacentes à motivação intrínseca, e às formas mais autorreguladas de motivação extrínseca são propostas pela TAD: $a$ necessidade de autonomia, a necessidade de competência e a necessidade de pertencer ou de estabelecer vínculos. Assim, o referencial teórico aqui abordado contempla os objetivos e a questão central dessa pesquisa.

Segundo Guimarães e Boruchovitch (2004), a satisfação das três necessidades é considerada essencial para o desenvolvimento e a saúde psicológica. Ainda segundo os mesmos autores, em um ambiente de ensino, é preciso que a mesma seja fonte de satisfação dessas três necessidades psicológicas básicas para que a motivação intrínseca e as formas autodeterminadas de motivação extrínseca possam ocorrer.

No trabalho de Martins e Langhi (2018) autonomia não significa o desejo de aprender algo sozinho ou conseguir o conhecimento por conta própria como um ato de individualismo ou desapego. Ao contrário, como apresentam Guimarães e Boruchovitch (2004), essa terminologia pode ser entendida como uma busca do conhecimento (ou algo) com ou sem auxilio, mas o que a determina, sob a visão da fundamentação teórica, é que a vontade de aprender deve partir de si mesmo, ou seja, o desejo de obter algo deve ser interno ao ser humano.

Já a necessidade de competência, segundo Reeve, Deci e Ryan (2004), é satisfeita quando o indivíduo busca e persiste em desafios adequados ao seu nível de desenvolvimento, mostra interesse em desenvolver atividades para seu crescimento psicológico e aperfeiçoamento das capacidades e habilidades próprias.

Somente a necessidade de competência não é suficiente para promover um aumento da motivação intrínseca. Segundo Guimarães e Boruchovitch (2004), torna-se necessário que a competência seja acompanhada por uma percepção de autonomia, ou seja, a situação não deve sufocar o senso de liberdade individual, por outro lado, o indivíduo precisa se sentir responsável pelo desempenho competente. 
Em relação à terceira necessidade, pertencer ou estabelecer vínculos, segundo Reeve, Deci e Ryan (2004), é considerada menos central quando comparada às demais, mas isso não significa que seja menos importante para a motivação intrínseca. Sentir-se parte de um contexto, pertencer a esse ambiente, pode ser considerado como pano de fundo para a satisfação das outras necessidades: competência e autonomia (ENGELMANN, 2010). Quando essa necessidade é satisfeita, o indivíduo se sente motivado para o relacionamento autêntico com o coletivo, aproximando-se daqueles que demonstram atenção e respeito em relação às suas peculiaridades (REEVE; DECI; RYAN, 2004).

De acordo com Ryan e Deci (2000), quando o ambiente possibilita suporte às necessidades de autonomia, competência e vínculo/pertencimento, os indivíduos sentem-se satisfeitos e envolvem-se ativamente nas atividades, possibilitando assim a manutenção ou o aumento da motivação intrínseca.

Para compreendermos melhor, o estudo da motivação intrínseca mostra que ela está relacionada com a competência, a autodeterminação e a autonomia. Já a motivação extrínseca está relacionada com a performance, que visa uma recompensa fornecida por um agente externo. Aqui os indivíduos se preocupam mais com o desempenho (notas) que com a aprendizagem.

Dentre as subteorias abordadas na TAD, a pesquisa focará nas três necessidades básicas, uma vez que apresentam termos considerados essenciais para o desenvolvimento psicológico para a motivação intrínseca. Dentro da análise dos dados, também buscaremos termos que remetem à motivação intrínseca e extrínseca descritos, principalmente, por Deci e Ryan (1985), emergentes dos participantes da atividade em questão. As demais subteorias da TAD também serão analisadas nesta pesquisa, mas como forma de complementar a análise dos dados.

\section{Objetivos}

\section{III.1 Objetivo Geral}

- Estudar quais aspectos motivacionais são encontrados em estudantes de uma disciplina de Astronomia desenvolvida em um ambiente formal de ensino e, a partir daí, identificar a influência dessa ciência na motivação desses indivíduos.

\section{III.2 Objetivo Específico}

- Investigar e elencar elementos indicadores das motivações extrínsecas e intrínsecas na disciplina ofertada;

- Dar subsídios para pesquisas futuras sobre atividades relacionadas à Astronomia e seu possível desempenho na motivação dos participantes. 


\section{Metodologia}

Esta pesquisa apresenta um delineamento de caráter empírico não experimental qualitativo com intervenção. Possui um delineamento de caráter empírico com intervenção, pois buscou na "realidade observável" os registros para obter seus dados e avaliar a extensão do efeito da intervenção feita pela pesquisa na população-alvo (ROSA,2011). Apresenta-se também uma análise qualitativa das informações obtidas, fundamentando-se na Análise Textual Discursiva (ATD) (MORAES, 2003), privilegiando a interpretação escrita dos conhecimentos constituídos. Este estudo possui um delineamento não experimental, pois não buscou controlar variáveis, ou seja, não foram utilizados grupos de controle.

Neves (1996) afirma que pesquisas qualitativas como essa, não buscam enumerar ou medir eventos e geralmente não empregam instrumentos estatísticos para a análise de dados, fazendo-se um contato direto e interativo do pesquisador com o campo de pesquisa. Tais tipos de pesquisa costumam privilegiar a interpretação dos dados obtidos, em que o pesquisador procura entender os fenômenos segundo a perspectiva dos participantes da pesquisa, interpretando os fenômenos estudados no local.

Neves (1996) afirma que pesquisas qualitativas como essa não buscam enumerar ou medir eventos e, geralmente não empregam instrumentos estatísticos para a análise de dados, proporcionando um contato direto e interativo do pesquisador com o campo de estudo. Tais tipos de investigações costumam privilegiar a interpretação dos elementos obtidos, em que o pesquisador procura entender os fenômenos motivacionais segundo a perspectiva dos participantes. Para tal, interpreta os acontecimentos observados no local.

Este trabalho propõe como referencial metodológico para a interpretação dos dados, a análise textual discursiva (ATD) proposta por Moraes (2003). Esse tipo de análise se baseia em uma rigorosa interação com a informação, objetivando a compreensão dos materiais obtidos na coleta. Segundo Moraes (2003), essa verificação qualitativa reforça o entendimento dos fenômenos ou informações que se propõe a investigar. Seu objetivo principal é a busca da clareza e da veracidade dos fatos investigados.

A ATD pode ser entendida, segundo Moraes (2003), como um processo de construção de novas percepções em que os novos conhecimentos seguem uma sequência recursiva a partir de três principais componentes propostos pelo referencial. São eles: desconstrução dos textos do corpus (unitarização), estabelecimento de relações entre os elementos unitários (a categorização), e o captar do novo emergente em que a nova concepção é comunicada e validada.

Para essa pesquisa, usamos os processos citados acima por Moraes (2003), Moraes e Galiazzi (2006), Moraes (1999) sobre a ATD como forma de referencial metodológico para a análise dos dados obtidos.

A análise se dividiu em três partes conforme o referencial. Na primeira, foram realizadas uma desconstrução e uma unitarização do corpus de pesquisa, que, em nosso caso, são os questionários respondidos. Nessa etapa, o corpus foi estudado minuciosamente e todas 
as informações úteis para a pesquisa foram fragmentadas conforme os seus objetivos. $\mathrm{Na}$ segunda parte, no processo de categorização, categorizou-se cada unidade fragmentada na primeira parte. Nesse momento elencamos nomes para cada uma dessas unidades conforme o referencial teórico abordado na pesquisa. Na terceira e última parte da análise, na construção do metatexto que expressa as interpretações sobre o corpus, construímos uma análise que aponta todos os significados possíveis conforme o referencial teórico, que foram detectados a partir do corpus da pesquisa. Com toda essa análise realizada, esperamos responder à questão central da pesquisa.

\section{IV.1 Contexto da pesquisa e caracterização da amostra pesquisada A Escola}

A pesquisa foi desenvolvida em uma escola de tempo integral denominada "Escola da Autoria", localizada em Campo Grande, MS. Esse é um novo modelo de escola implantado em 2017 no referido estado, onde hoje são 16 escolas ao todo com essa nova metodologia implantado. Essa tem como objetivo a formação de sujeitos críticos, autônomos, protagonistas, indivíduos capazes de tomar decisões e fazer escolhas embasadas no conhecimento, na reflexão, na consideração de si próprio e do coletivo, focando principalmente em seu "projeto de vida" (ICE,2015).

$\mathrm{Na}$ escola da Autoria, os estudantes possuem disciplinas do currículo comum e outras da parte diversificada, que são especificas desse modelo de escola como: projeto de vida, disciplinas eletivas (eletiva I, II e III), pesquisa e autoria I, pesquisa e autoria II e pós-médio. Os estudantes possuem nove aulas por dia e três refeições, além de clubes recreativos organizados por eles próprios, treinos esportivos, atividades extraclasses, tutoria (em que o discente pode ter orientações de assuntos extracurriculares com algum funcionário da escola escolhido por ele), etc.

Para atender as demandas exigidas para esse modelo de ensino integral, a referida escola teve de passar por adequações em relação à infraestrutura. Tais medidas foram realizadas, na maior parte, durante o ano letivo, o que causou, em alguns momentos, um desconforto para os estudantes e funcionários.

\section{A Eletiva "Conceitos Básicos de Astronomia e a construção de matérias didáticos"}

No começo do primeiro semestre de 2018, foi indagado para cada uma das treze turmas da escola, por meio de um questionário, quais tópicos (disciplinas) gostariam que fossem ministrados nas eletivas no semestre em questão. Com os resultados em mãos, foram relacionadas às sugestões dos estudantes e avaliadas pelos professores, uma vez que existe a necessidade da capacitação desses profissionais para ministrarem as disciplinas.

Constatou-se que as sugestões mais citadas pelos estudantes foram temas relacionados a jogos esportivos e Astronomia. Uma vez que a eletiva deve ser uma disciplina com metodologia e conteúdo diferenciado (em relação à base comum) e algo sugerido pelos 
educandos, verificou-se a necessidade de ofertar algo que fosse relacionado ao universo da Astronomia, já essa não é uma área contemplada de maneira específica no currículo da base comum. Essa decisão foi concebida juntamente com várias concepções espontâneas dos estudantes frente ao tema, assim como pontuam Langhi e Nardi (2010).

Com vistas a uma nova metodologia e a um tema diferenciado e sugerido pelos estudantes, o professor (e pesquisador) de Física ofertou a eletiva chamada: Conceitos básicos de Astronomia e a construção de materiais didáticos.

Ao todo, treze disciplinas eletivas foram ofertadas pelos professores, sendo que cada uma delas possuía 34 vagas que deveriam ser preenchidas. Esse número se deu em função da quantidade de turmas (salas de aula) que a escola possuía na época, sendo que, via de regra, cada eletiva deveria ter um número igual de vagas. Aos estudantes era dada a oportunidade de optarem por apenas uma para participar durante todo o semestre. Caso a primeira opção do candidato estivesse com todas as vagas preenchidas, ele deveria escolher outra que ainda possuísse vagas disponíveis, até se inscrever em alguma.

É importante ressaltar que a eletiva apresentava nota, ou seja, era atribuído até um ponto na média para todas as disciplinas da base comum. O professor responsável pela eletiva era o que atribuía essa nota de acordo com as suas avaliações durante o semestre. Por isso, os estudantes eram obrigados a escolher uma dentre as 13 eletivas, pois um dos dez pontos da média bimestral era obtido através do desempenho do aluno nessa parte diversificada.

Uma vez distribuídas as eletivas, os estudantes tiveram dois dias de inscrições via internet. Após esse período, as aulas foram divididas em dois tempos seguidos de 50 minutos por semana.

\section{A sequência didática}

Os temas abordados nas aulas da eletiva em questão foram, em sua maioria, relacionados a assuntos que pesquisas como a de Langhi e Nardi (2010) sugerem que o público em geral apresenta várias concepções espontâneas a respeito. Portanto, todos os conteúdos ministrados durante aquele semestre foram abordados com o intuito de diminuir o máximo possível tais concepções equivocadas.

As aulas foram expositivas, demonstrativas, audiovisuais, observacionais (observação do céu noturno) e com a construção de pequenos materiais didáticos. Todas as exposições foram ministradas com uma metodologia diferenciada das tradicionais com o objetivo de tornar o processo de ensino-aprendizagem prazeroso ao aluno o que segue criteriosamente as orientações da parte diversificada do currículo da escola da Autoria (ICE, 2015).

Os temas abordados nas aulas foram, em sequência: o que é a Astronomia e suas divisões; Astronomia X Astrologia; Geocentrismo X Heliocentrismo; Fases da Lua; Eclipses; Estações do ano; construção de um relógio solar de garrafa pet; Observação do céu noturno 
por meio de um telescópio; construção de um relógio estelar; Forma da Terra e construção de um sistema solar em escala de tamanho e distância.

Aqui destacamos a parceria feita com o clube de ciência "Carl Sagan" da Universidade Federal de Mato Grosso do Sul (UFMS), que para as aulas sobre as fases da Lua, forneceu materiais didáticos para demonstrar os conceitos envolvidos e, na observação do céu noturno, concedeu monitores (acadêmicos) e o telescópio. A atividade de observação foi realizada em uma noite de céu sem nuvens e com Lua crescente (melhor fase para se observar o céu). Os estudantes levaram autorizações dos pais assinadas para que pudessem estar na escola fora do horário letivo.

Ao final do semestre, os materiais produzidos e um "quiz" elaborado pelos estudantes com perguntas sobre Astronomia foram apresentados à escola como trabalho de finalização, ou seja, a culminância de todas as eletivas. Esse momento é o encerramento das atividades do semestre, em que os estudantes têm a oportunidade de divulgarem para o público (colegas, funcionários e comunidade escolar) o que desenvolveram durante as aulas. Essa iniciativa é recomentada pela coordenação da escola com o objetivo de elucidar, incentivar e demonstrar à comunidade escolar e local o que foi produzido pelos alunos, sendo uma forma eficaz de aproximar a população da escola.

\section{Instrumento de coleta de dados}

Para o presente estudo, foram utilizados como fonte de dados principal os questionários respondidos pelos estudantes da eletiva em questão. Segundo Gil (2008), essa pode ser considerada como uma técnica de investigação composta por um conjunto de questões que são submetidas a indivíduos com o propósito de obter informações sobre conhecimentos, crenças, sentimentos, comportamento presente ou passado, entre outros.

No questionário (apêndice I), não foi necessário que os estudantes se identificassem, pois, pretendíamos preservar as identidades para que eles pudessem se sentir mais confortáveis ao responderem, o que, segundo Gil (2008), é uma das vantagens de se usar esse instrumento de coleta de dados.

Uma vez que Langhi e Martins (2018) elaboraram um questionário com o objetivo de encontrar indícios de aspectos motivacionais em uma atividade realizada em um espaço não escolar, nós o utilizamos como modelo, fazendo as adequações necessárias de acordo com a realidade da pesquisa proposta, a fim de obter respostas satisfatórias para se responder à questão central de pesquisa. Cada questão foi pensada de acordo com os objetivos da pesquisa. Assim, o questionário produzido contém nove questões abertas, nas quais pretendemos privilegiar a escrita e os sentimentos dos estudantes frente às atividades desenvolvidas no semestre.

As questões quatro e cinco não foram analisadas neste estudo, pois referem-se aos conteúdos ministrados e não aos aspectos motivacionais dos participantes. Tais questões poderão ser analisadas em outro trabalho com o objetivo de entender a relação entre os temas 
mais solicitados pelos estudantes e suas concepções. Assim, para esta pesquisa, serão analisadas sete questões ao todo, com o principal objetivo de identificar indícios que remetem à motivação intrínseca ou extrínseca nas respostas dos estudantes.

Para poder aplicar o questionário de maneira mais fidedigna possível, ele passou por processos de validações, a fim de torná-lo mais coerente com os objetivos da pesquisa. Após um esboço inicial, as questões foram encaminhadas a dois professores doutores na área de educação e ensino de ciências, a fim de exporem suas críticas e sugestões. Todas as observações enviadas por esses profissionais foram analisadas cuidadosamente e aplicadas com vistas à adequação e ratificação desse material. Em seguida, foi aplicado um teste piloto para apenas $10 \%$ da turma, ou seja, assim como aponta Canhota (2008), a quantidade de participantes para esse tipo de teste não precisa ser superior a essa porcentagem. Esse público foi escolhido de modo aleatório e os dados aqui obtidos não fizeram parte das análises finais da pesquisa. Tal teste foi aplicado a fim de verificar a fidedignidade da enquete.

Para a psicologia, os questionários que buscam detectar indícios de motivação escolar costumam possuir um número maior de questões que privilegiam uma análise mais quantitativa em escala, assim como mostra em seu estudo Cordeiro (2010), que usou as "Escalas do Questionário de Motivação Escolar (QME)". Para a área de ensino de ciência, que se dedique mais a uma análise qualitativa, tal questionário em escala não se mostraria adequado, pois, assim como aponta Martins (2014), análises quantitativas podem perder dados preciosos, uma vez que uma análise qualitativa trabalha valores e não somente respostas predefinidas, trabalhando melhor a compreensão das opiniões dos indivíduos. Assim, justificou-se um número menor de questões no questionário deste estudo, mas que atendeu os objetivos definidos a priori.

Após os processos de validações citados, realizamos as modificações necessárias no questionário e chegamos a uma versão final que acreditamos ser a melhor possível para a realização pesquisa.

Aplicamos a versão final do questionário no último dia de aula da eletiva, uma vez que desejávamos estudar os aspectos motivacionais dos estudantes apresentados no período das aulas, ou seja, buscávamos identificar esses aspectos desde o primeiro até o último dia de aula.

\section{Análise de dados e resultados}

Essa etapa da análise envolveu o estudo dos dados de pesquisa coletados, ou seja, a análise dos questionários respondidos pelos estudantes frente aos referenciais teórico e metodológico abordados.

Seguindo o referencial metodológico de análise de dados adotado, durante essa etapa da ATD, buscamos fragmentar cada aspecto que possa indicar indícios de motivação intrínseca ou extrínseca nos questionários respondidos pelos estudantes da eletiva. 
Sob à luz da ATD e considerando que anteriormente à análise já se possuía um objetivo central nesta pesquisa, adotamos o método dedutivo, ou seja, as categorias foram definidas a priori antes da leitura do corpus de análise, seguindo os objetivos da pesquisa por meio do referencial teórico (TAD), uma vez que nosso referencial metodológico dá abertura para esse procedimento (MORAES, 2003). Apesar de existirem categorias já definidas, não descartamos o surgimento de novas categorias após a análise da coletânea de dados, ou seja, há possibilidades de categorias emergentes, sendo obtidas por meio do método indutivo, segundo Moraes (2003).

No presente estudo, as análises evoluíram conforme as seguintes categorias a priori:

1. Autonomia;

2. Competência;

\section{Pertencimento.}

Essas categorias foram assim definas inicialmente devido ao objetivo e à questão central da pesquisa, pois estão diretamente relacionadas a esses três componentes, uma vez que procurávamos identificar indícios de motivação nos estudantes.

Como são apresentadas na $\mathrm{TAD}$, essas três categorias fazem parte das três necessidades básicas apresentadas por Ryan e Deci (2002). Além dessas, os autores citam também a teoria da avaliação cognitiva, teoria da causalidade e a teoria da integração organísmica como características para a compreensão da motivação humana. Porém, elas não fazem parte das principais categorias a serem analisadas, uma vez que, segundo os próprios autores, as três necessidades básicas são a fonte da motivação humana, sendo que as demais surgem a partir dela e funcionam com um complemento para a caracterização da motivação.

O questionário da pesquisa foi elaborado de forma que conseguisse identificar, por meio das respostas dos participantes, principalmente as três categorias citadas obtidas a priori nesta pesquisa.

Um fato que chamou a atenção foi a grande procura dos estudantes para se inscreverem na eletiva em questão. Foram 96 solicitações de inscrições, porém somente 34 vagas eram ofertadas por disciplina. Isso mostra que os estudantes estavam, de algum modo, interessados ou ainda motivados ao procurarem participar das aulas sobre Astronomia, evidenciando, assim como aponta Langhi e Nardi (2010), que essa ciência possui, em si própria, um fator que chama a atenção, que desperta a curiosidade e a motivação dos envolvidos.

Devido ao espaço reduzido do trabalho, não será possível apresentar a análise minuciosa dos 27 questionários respondidos pelos estudantes da eletiva. Assim, colocamos a seguir cada pergunta, seguias de quais indícios motivacionais pretendemos identificar, além de uma análise geral com alguns trechos das respostas dos discentes. 


\section{Questionário e a análise das respostas}

1) Você participou dessa eletiva por vontade própria ou alguém externo (familiares, amigos, etc.) pediu a você para participar?

Aqui, buscamos identificar a necessidade da autonomia, pois por meio de sua resposta, é possível identificar quais estudantes demonstraram possuir vontade própria em participar da eletiva e quem foi influenciado por alguém externo a participar.

Se o estudante se inscreveu na eletiva por vontade própria, isso mostra, segundo Guimarães e Boruchovitch (2004), o ato de governar por si próprio, ou seja, mostra a sua liberdade de escolha e expressão, contribuindo para a autonomia e, consequentemente, para a motivação intrínseca (interna). Caso o aluno tenha participado da eletiva devido a alguém ou algo externo, a motivação interna pode não ocorrer, uma vez que ele não teve liberdade de escolha, participando somente para satisfazer algo externo.

Com a análise dessa questão, observou-se que 26 estudantes responderam: "Por vontade própria".

Por meio dos questionários respondidos, foi possível encontrar indícios de autonomia dos participantes perante a eletiva escolhida. Chegamos a essa conclusão, pois quando um indivíduo participa por vontade própria de alguma atividade, notamos a liberdade de escolha e expressão, o que contribui para a autonomia e, consequentemente, para a motivação intrínseca, como aponta Guimarães e Boruchovitch (2004) e Deci e Ryan (1985). Concluímos também que a origem da ação do locus de causalidade foi interna, uma vez que identificamos indícios de autonomia e, segundo Guimarães e Boruchovitch (2004), quando um indivíduo realiza uma atividade por vontade própria, ele sempre apresentará um locus de causalidade interna, contribuindo também para a sua motivação intrínseca.

Em apenas um questionário foi encontrada a seguinte resposta: "um amigo e acho interessante". Aqui, notamos que, apesar de o estudante afirmar que alguém externo a ele o convidou a participar da eletiva, ele se inscreveu por se interessar, de alguma forma, pelo tema abordado. Isso mostra que o locus de causalidade foi interno a esse indivíduo, pois mesmo com o convite de alguém externo, ele se inscreveu na eletiva por admirar os temas propostos, contribuindo, assim, para a sua autonomia.

2) Comente e explique sobre o que o motivou a participar dessa eletiva?

Essa questão buscou complementar a anterior, pois é possível identificar aqui, por meio da origem do locus de causalidade, o que provocou a ação, ou seja, o que fez com que o estudante se sentisse autônomo ou não frente ao tema.

As características ligadas à motivação intrínseca ou extrínseca poderão ser identificadas nessa questão, uma vez que a escrita do participante irá mostrar o que o motivou a participar da eletiva, seja algo interno ou externo a ele. Assim, poderá classificar em qual característica da motivação melhor se encaixa essa escrita.

Para essa questão, foram encontradas respostas como: "Porque gosto de astronomia"; "Saber mais sobre o universo, e porque desde pequena sempre tive o 
interesse"; Gostei do assunto e da proposta apresentada pelo professor"; "Amo Astronomia"; Sempre gostei de astronomia”; Curiosidade pela galáxia”; "Gosto das estrelas"; "Curiosidade pela observação"; "As atividades que seriam elaboradas"; entre outras diversas respostas.

Como forma de complementar a questão anterior, notamos aqui, em todos os questionários respondidos, que a ação ou causa da origem do locus de causalidade interna foi o fato de os participantes apresentarem, de modo geral, o interesse pelo estudo da Astronomia, que surgiu pela curiosidade em aprender mais sobre os temas abordados, por nunca ter estudado algo sobre o assunto, pelo fato de nunca ter observado pelo telescópio, pela disposição em produzir os materiais didáticos, etc.

Tais aspectos apresentados pelos estudantes mostram o prazer que eles têm em participar da eletiva, sendo que algo interno fez-nos ter a iniciativa de participar das atividades que, consequentemente, contribuíram para a motivação intrínseca, como mostram Guimarães e Boruchovitch (2004).

Ressalta-se que nenhum estudante respondeu que sua motivação em participar da eletiva foi o ponto atribuído na média. Isso mostra que o locus de causalidade foi interno e que o fator externo não foi determinante para a participação.

3) Comente e explique como foi a sua interação com o professor da eletiva, com os monitores da casa da ciência da UFMS (caso participou dessa atividade) e os colegas de classe durante as atividades desenvolvidas.

Essa questão buscou identificar a necessidade de pertencimento, pois aqui se registra como ocorreu a interação dos estudantes com os demais integrantes das atividades desenvolvidas. Essa interação é importante acontecer de maneira positiva, pois, segundo Engelmann (2010), o indivíduo deve se sentir aceito por todos à sua volta e ter uma relação segura com eles para que possa ocorrer a motivação.

Para essa questão, foram encontradas respostas como: "Gostei bastante por conta de estar com pessoas que curte o mesmo assunto"; "Foi legal”; "Amigável, não teve conflitos"; "Muito boa, interagiram com os alunos e essa experiência foi muito empolgante"; "São todos atenciosos e o professor muito paciente"; "Foi tranquilo, todos muitos simpáticos", entre outras diversas respostas.

Com as respostas dadas pelos estudantes, pode-se observar que todos os questionários respondidos apresentaram indícios de pertencimento frente à participação na eletiva. Isso pode ser observado, pois as interações dos estudantes com os monitores, com o professor e com os colegas de sala de aula, foram, de alguma forma, agradáveis para eles, uma vez que isso aconteceu devido à boa conduta apresentada e pela atenção demostrada por todos os envolvidos. Segundo Ryan e Deci (2002), essa interação com os demais integrantes da atividade é importante para que o indivíduo se sinta bem recebido no ambiente para que possa desenvolver todas as atividades com entusiasmo, contribuindo, assim, para a sua motivação. 
6) Após a sua participação nessa eletiva, comente e explique se você sentiu-se interessado em participar de outras atividades relacionadas ao estudo da Astronomia.

Aqui, buscamos identificar indícios da necessidade de autonomia, competência $e$ pertencimento, pois se o estudante da eletiva se sentir interessado em participar novamente dessa ou de outras atividades relacionadas à Astronomia, podemos encontrar indícios de motivação intrínseca, uma vez que, segundo Ryan e Deci (2000), quando um indivíduo mostra o interesse de estar em um ambiente, de participar da atividade e buscar mais informações sobre ela, mostra possuir as três necessidades básicas essenciais para a motivação interna.

Nessa questão, foram encontradas respostas como: "Sim, sempre tive essa vontade"; "Sim, com observações e estudos mais aprofundados"; "Sim, pelo fato de ser um assunto curioso e sempre querer saber mais"; "Sim seria bacana me aprofundar mais"; "Sim, pois obtive conhecimento sobre tudo que eu tinha dúvidas", "Claro descobrir mais coisas sobre o universo é muito bom"; "Sim, agora que estou mais empolgado", entre outras diversas respostas.

Com a análise das respostas dos estudantes por meio do questionário, pudemos constatar que todos apresentaram indícios de autonomia, competência e pertencimento. Chegamos a essa conclusão pois, ao responderem que de alguma forma pretendem participar de outras atividades relacionadas à Astronomia, eles apresentaram indícios de estarem motivados intrinsecamente para esse tipo de tema e/ou atividade. Segundo Ryan e Deci (2000), quando um indivíduo mostra o interesse de estar em um ambiente, de participar da atividade e buscar mais informações sobre ela, ele mostrou possuir as três necessidades básicas essenciais para a motivação interna de um indivíduo.

Uma resposta encontrada no questionário chamou a atenção, a saber: "Não muito, pois senti vontade de estudar coisas além disso”. Pode-se observar que o estudante apresentou indícios de motivação intrínseca, uma vez que demonstrou o interesse em buscar informações além dos conteúdos ministrados em sala de aula, ou seja, mostrou estar motivado suficientemente para aperfeiçoar seus conhecimentos, mesmo que possam estar além do seu nível cognitivo naquele momento.

7) Comente e explique, se após a realização dessa eletiva você se sente capaz de buscar mais conhecimentos sobre os temas abordados.

Aqui, buscou-se identificar a competência, pois assim como apontam Reeve, Deci e Ryan (2004) quando o indivíduo busca algo além da atividade que seja um desafio adequado ao seu nível cognitivo, mostra o interesse de desenvolver suas habilidades frente ao tema. Assim, a atividade realizada pode ter proporcionado um desenvolvimento psicológico, mostrando indícios de motivação neste participante.

Algumas respostas encontras foram: "Sim, pois o universo é infinito assim como seus mistérios"; "Lógico! Já gostava, agora gosto mais ainda"; "Sim, pois fiquei com vontade de aprender mais"; "Sim, esses temas me fizeram aumentar a curiosidade minha"; "Sim, pois a 
eletiva me deixou curiosa para saber mais sobre o espaço"; "Me sinto capaz, pois aprendi bastante na eletiva e tenho vontade de aprofundar os assuntos"; Claro que sim, quem não se interessa por Astronomia", entre outras diversas respostas.

Com as respostas dadas pelos estudantes, observou-se que todos apresentaram indícios de competência frente aos temas abordados. Caracteriza-se tal fato, pois quando um indivíduo se sente capaz de aprender e de buscar um conhecimento além da atividade desenvolvida, sendo este um desafio ao seu nível cognitivo, o estudante mostra o seu interesse em desenvolver habilidades sobre os temas, contribuindo assim para a sua motivação intrínseca como aponta Reeve, Deci e Ryan (2004).

8) Comente e explique se, durante toda a eletiva você se sentiu gratificado ao realizála.

Essa questão buscou identificar indícios de competência nos participantes, uma vez que a capacidade deles de interagir satisfatoriamente com a atividade pode proporcionar uma maior segurança e confiança para realizá-la, assim como aponta Guimarães e Boruchovitch (2004). Essa gratificação seria um indício de motivação para o próprio participante, podendo aqui ser identificada.

Para essa questão, foram encontradas respostas como: "Sim adquiri muito conhecimento"; "Sim, principalmente pela observação que sempre tive vontade"; "Essas coisas abriram minha mente muito"; "Foi muito gratificante, pois aprendi o que esperava e conheci os planetas"; "Sim, pois muitas pessoas queriam entrar participar e eu consegui entrar; "Com certeza, através da eletiva, pude tirar algumas dúvidas em relação ao tema"; "Sim, realizei sonhos e também obtive muito conhecimento", entre outras diversas respostas.

As respostas dadas pelos estudantes remetem a indícios de competência frente à atividade desenvolvida. Tal fato pode ser entendido, pois quando o indivíduo interage satisfatoriamente com o que é proposto a ele, proporciona uma maior confiança e segurança para que o realize, contribuindo, assim, para a motivação intrínseca, como aponta Guimarães e Boruchovitch (2004) e Reeve, Deci e Ryan (2004).

9) Comente e explique se, para você, os locais onde as atividades foram realizadas foi adequado.

Tal questão buscou identificar a necessidade de pertencimento, uma vez que, segundo Engelmann (2010), para ocorrer a motivação, o indivíduo deve se sentir, de alguma forma, parte do ambiente em que se encontra, ou seja, deve pertencer ao local. Esse item identificou quais participantes se sentiram pertencentes ao local onde as atividades da eletiva foram desenvolvidas.

Para essa questão, foram encontradas respostas como: "Acho que uma sala temática seria melhor"; "O local não foi tão adequado, mas foi o suficiente para fazer uma boa observação e ganhar conhecimento"; "Sim, mas poderia ser mais escura a sala"; "Sim, 
muito bom"; "Não muito barulho e as vezes a claridade atrapalhou”; "Foi sim"; "Sim foi muito bom o local"; "Sim, na escola", entre outras diversas respostas.

Pudemos identificar, por meio das respostas, que 15 estudantes apresentaram indícios de pertencimento em relação aos locais onde foram realizadas as atividades. Isso foi constatado porque os estudantes se sentiram, de alguma forma, parte do ambiente onde se encontravam, seja em relação à segurança, ao conforto, à comodidade, entre outros fatores, contribuindo, assim, para a motivação intrínseca, como apontam Engelmann (2010) e Deci e Ryan (1985).

Já para 12 estudantes, o local onde as atividades foram desenvolvidas poderia ser, de alguma forma, "melhor". Alguns relataram que a claridade da sala e os ruídos provocados pelas obras atrapalharam o andamento das atividades realizadas em sala de aula. O primeiro inconveniente se justifica pela falta de cortinas na sala, já que, em algumas aulas, necessitavase de um ambiente sem luminosidade. Já o segundo, justifica-se pela reforma, durante todo o ano letivo e no horário de aula, que a escola teve de realizar para poder atender os estudantes no novo modelo de escola integral.

Para esses alunos, fatores externos atrapalharam, de certa maneira, seu envolvimento com o ambiente, mostrando que o pertencimento em relação a esse espaço, no qual estavam inseridos, não aconteceu por completo.

A seguir, apresentamos um quadro que sintetiza os principais aspectos e características motivacionais encontrados e levantados por meio da pesquisa em questão.

Quadro 1 - Síntese dos principais aspectos motivacionais encontrados. Fonte: os autores.

\begin{tabular}{|c|c|}
\hline CATEGORIAS & PALAVRAS-CHAVE \\
\hline Autonomia & $\begin{array}{c}\text { Vontade própria; aprender; estudar; fazer algo novo; buscar } \\
\text { conhecimento; realização; curiosidade; oportunidade. }\end{array}$ \\
\hline Competência & $\begin{array}{c}\text { Gratificação; competente; capaz; dificuldades; buscar } \\
\text { conhecimento; realização de sonhos; estudar; compreender. }\end{array}$ \\
\hline Pertencimento & $\begin{array}{c}\text { Interação; local; bem-estar; boa relação; amigável; adequado; } \\
\text { sala de aula. }\end{array}$ \\
\hline
\end{tabular}

Com todos os dados analisados por meio do referencial teórico adotado incialmente, apesentamos a seguir um quadro que revela a quantidade de estudantes que mostraram possuir indícios das três principais categorias obtidas a priori nessa pesquisa. A necessidade do pertencimento foi dividida em duas partes com o objetivo de mostrar a diferença entre os dois momentos que se referem a essa necessidade. 
Quadro 2 - Questionários que apresentaram as três necessidades básicas. Fonte: os autores.

\begin{tabular}{|c|c|}
\hline TRÊS PRINCIPAIS CATEGORIAS & TOTAL \\
\hline Autonomia & 27 \\
\hline Competência & 27 \\
\hline Pertencimento (Interação/professor/estudante) & 27 \\
\hline Pertencimento (Local) & 13 \\
\hline
\end{tabular}

A seguir, apresentamos outro quadro que revela quais estudantes demonstraram possuir indícios de motivação intrínseca ou de motivação extrínseca. A sequência numérica dos questionários para a análise foi feita à medida que eram entregues respondidos, ou seja, o primeiro questionário entregue foi numerado como 01, o segundo como 02, assim sucessivamente.

Quadro 3 - Questionários que apresentaram as três principais categorias. Fonte: os autores.

\begin{tabular}{|c|c|c|}
\hline MOTIVAÇÃO & NÚMEROS DOS QUESTIONÁRIOS & TOTAL \\
\hline \multirow{2}{*}{ Motivação Intrínseca } & $\begin{array}{l}01 ; 02 ; 03 ; 04 ; 05 ; 06 ; 07 ; 08 ; 09 ; 10 ; 11 ; 12 ; 13 ; 14 ; 15 ; \\
16 ; 17 ; 18 ; 19 ; 20 ; 21 ; 22 ; 23 ; 24 ; 25 ; 26 ; 27 .\end{array}$ & 27 \\
\hline Motivação Extrínseca & ----- & 00 \\
\hline
\end{tabular}

A análise dos dados apresentada foi qualitativa, assim, integraram-se os resultados da análise dos questionários respondidos pelos estudantes da eletiva. Portanto, a partir das categorias acima interpretadas, apresentamos, a seguir, a última etapa da Análise Textual Discursiva que, segundo Moraes (2003), indica uma nova compreensão a partir do referencial teórico abordado inicialmente, a saber, os aspectos motivacionais encontrados nos estudantes da eletiva proposta por essa pesquisa.

Constatamos, por meio dos questionários respondidos e analisados, que $100 \%$ dos estudantes apresentaram possuir autonomia suficiente para participar, por vontade própria, da atividade em questão, mostrando possuir, segundo Guimarães e Boruchovitch (2004), a faculdade de se governar por si mesmo, ou seja, manifestando dispor de uma liberdade de escolha própria, o que contribui, segundo Ryan e Deci (2002), para a motivação intrínseca.

É importante lembrar que a participação na eletiva era obrigatória para todos os estudantes da escola, pois era atribuído até um ponto na média para todas as disciplinas. Porém, em nenhum momento durante as aulas e nos questionários respondidos, esse fator (ponto na média) foi citado pelos estudantes como algo que os influenciou a participarem. Assim, pode-se inferimos que o fator externo não influenciou na autonomia dos estudantes ao 
participarem da eletiva de Astronomia e que sua escolha foi interna com o objetivo de uma realização pessoal.

A análise, também, que $100 \%$ dos estudantes apresentaram possuir a necessidade de competência ao participar da eletiva, ou seja, eles se mostraram gratificados ao participarem e não mostraram dificuldades em compreender ou em buscar mais informações sobre os temas abordados nas aulas, contribuindo segundo Ryan e Deci (2000), para a motivação intrínseca. Aqui, percebe-se a necessidade de atividades diferenciadas como as que foram desenvolvidas em um ambiente escolar de ensino, pois forneceram a possibilidade de os estudantes expressarem confiança, segurança ao desenvolver as atividades e eficiência ao compreender o tema abordado.

Conclui-se, também, que $100 \%$ dos estudantes mostraram possuir a necessidade de pertencimento em relação à interação com o professor, monitores e os colegas de classe. Assim, os eles manifestaram se sentir parte do ambiente onde se encontravam, contribuindo, segundo Ryan e Deci (2002), para a motivação intrínseca. Nesse momento, percebeu-se por meio das respostas obtidas que esse tipo de atividade desenvolvida em um ambiente escolar de ensino, forneceu vínculo emocional, relações interpessoais e uma relação segura com os integrantes.

Por outro lado, apenas $55 \%$ dos estudantes apresentaram a necessidade do pertencimento em relação ao local onde as atividades foram desenvolvidas. Os demais, não compartilharam desse sentimento e as justificavas mais encontradas em suas respostas foram: a dificuldade de se concentrar com os ruídos provocados pelas obras na escola e, em algumas ocasiões, a claridade da sala de aula que atrapalhava o desenvolvimento de algumas atividades.

Contudo, esses estudantes, mesmo não apresentando a necessidade do pertencimento em relação ao local onde as aulas foram desenvolvidas, apresentaram tal necessidade em relação à interação com o professor, monitores e os colegas de turma. Segundo Ryan e Deci (2002), a necessidade de pertencimento faz parte das três necessidades básicas para que a motivação intrínseca possa ocorrer, porém, ainda segundo os autores, essa necessidade é a menos central, ou seja, um indivíduo pode estar motivado intrinsicamente sem que essa necessidade seja satisfeita completamente, desde que as outras sejam supridas por completo. É importante ressaltar que, em nenhum momento, algum estudante demostrou a vontade de trocar de eletiva (o que era permitido) devido a esses fatores externos citados, o que indica que tais problemas não foram um fator determinante para que se sentissem desmotivados em relação às atividades.

Com toda análise realizada por meio do referencial teórico abordado, pudemos concluir que todos os estudantes que responderam o questionário apresentam indícios de motivação intrínseca ou o seu nível mais autodeterminado (o mais próximo da motivação intrínseca) frente às aulas da eletiva. Nenhum estudante apresentou indícios de motivação extrínseca, mesmo com fatores externos, como a obrigatoriedade da escolha de uma eletiva e 
a pontuação na média, não influenciaram a escolha dos estudantes, mostrando a liberdade de escolha deles, contribuindo para a motivação intrínseca.

Assim, verifica-se que atividades como essa, realizadas em espaços escolares, são viáveis para o ensino, pois além de apresentar estudantes potencialmente motivados intrinsecamente, permite que eles desenvolvam projetos extracurriculares, uma vez que não existe na grade escolar disciplinas relacionadas à Astronomia. Como apontam Langhi (2004), Langhi e Nardi (2010), entre outros, os estudantes terminam o ensino básico e, até mesmo o superior, com várias concepções espontâneas sobre o tema, reforçando a necessidade de atividades relacionadas a essa ciência, tanto em espaços escolares como não-escolares. Essa motivação intrínseca apresentada por esses estudantes nessa atividade especifica, pode contribuir, consequentemente, para a aprendizagem (mesmo que a pesquisa não tinha esse objetivo), assim como aponta Engelmann (2010) e Langhi e Martins (2018).

A partir da análise realizada, não foi possível identificar nenhuma nova categoria que se diferenciasse das definidas a priori, ou seja, não foi identificada nenhuma categoria emergente a partir da leitura e análise do corpus de texto.

Com todo o processo de análise realizado, constata-se neste estudo, que, de fato, como apontam Langhi (2004), Kantor (2001), Langhi (2009), entre outros, a Astronomia possui um caráter potencialmente motivacional, ou seja, a partir de uma análise detalhada por meio de um referencial teórico sobre motivação em que julgasse ser o adequado para essa pesquisa, encontramos indivíduos que apresentaram indícios de autonomia, competência e pertencimento, o que remete a sujeitos motivados intrinsicamente ao participarem de uma atividade envolvendo o estudo da Astronomia.

Sob a perspectiva da TAD, a inserção de atividades que envolvam o estudo da Astronomia em ambientes formais (escolar) de ensino, deve ser uma prática constante, pois, como aqui constatado, e também na pesquisa de Langhi e Martins (2018), que utilizou um referencial teórico adequado para estudar os aspectos motivacionais em um ambiente não escolar, atividades assim podem proporcionar novas satisfações, gratificações, interações, prazer, realizações, desejos, entre outros termos que podem levar um indivíduo à motivação intrínseca.

Nos questionários analisados, foram encontradas características como: realização pessoal, curiosidade, vontade de aprender, sonhos, gratificação, busca de algo novo, entre outras, que foram responsáveis pela motivação intrínseca dos estudantes frente à participação nas atividades propostas. Isso mostra que atividades realizadas em um ambiente escolar de ensino devem despertar em seus participantes, ao menos, essas características, pois eles somente participarão de uma atividade com autonomia se ela despertar ou proporcionar um sentimento de gratificação ou satisfação inerente, que está relacionado diretamente com a motivação. 


\section{Considerações finais}

No decorrer do semestre letivo, alguns estudantes foram transferidos de outras escolas, o que explica um número menor de questionários respondidos em relação ao número de inscritos inicialmente na eletiva, uma vez que as respostas foram efetuadas no último dia de aula do semestre.

Em relação à observação noturna do céu por meio do telescópio, dos 34 estudantes frequentes na eletiva, apenas 25 conseguiram autorização dos pais para ir à escola no período noturno para realizar a atividade. Os demais, que não puderam comparecer, alegaram que já tinham compromisso no dia, que os pais não autorizaram a sua ida à escola naquele horário ou, ainda, que não tinham condução. A não participação do estudante nessa proposição não significa que eles não apresentaram motivação em relação à eletiva ou à atividade, mas que, por algum motivo que não dependia deles, não tiveram a oportunidade de participar.

Com relação ao andamento da eletiva durante o semestre, as aulas ocorreram normalmente, seguindo um cronograma de conteúdos e atividades elaborado previamente. Após a construção dos materiais didáticos, como o relógio solar de garrafa Pet e o relógio estelar, os estudantes demonstraram um entusiasmo e "surpresa" durante a sua elaboração, pois relataram que não sabiam que era possível medir o tempo por meio de materiais tão simples. No grupo do aplicativo WhatsApp da eletiva, vários estudantes postaram fotos utilizando seus materiais produzidos em sala, mostrando que ficaram gratificados com a atividade, o que segundo Ryan e Deci (2002), contribui para a motivação intrínseca.

A partir dos aspectos motivacionais encontrados nos estudantes da eletiva de Astronomia, concluímos que 100\% desses alunos apresentaram indícios de motivação intrínseca ao participar das atividades propostas pela eletiva, ou seja, a partir dos questionários respondidos e analisados por meio do referencial teórico da TAD, verificamos que eles mostraram estar motivados intrinsecamente frente ao tema abordado.

Autores como Langhi (2004), Kantor (2001), Langhi (2009), entre outros, colocam que a Astronomia é motivacional em qualquer ambiente de ensino, mas nenhum deles se baseia em um referencial teórico sobre motivação para comprovar tal afirmação. Apenas o trabalho de Langhi e Martins (2018) traz uma análise desses aspectos no ensino dessa ciência, porém faz essa análise em um ambiente não escolar. Assim, realizamos esta pesquisa com o objetivo de constatar e verificar, por meio de um referencial teórico sobre motivação, se a Astronomia realmente pode ser considerada potencialmente motivacional em um ambiente escolar de ensino.

Ao apresentarmos a conclusão de que a Astronomia é potencialmente uma ciência motivadora, constatando isso por meio de um referencial teórico que jugamos ser adequado, ressaltamos que este foi um estudo para a situação-problema colocada incialmente nesta pesquisa para um grupo específico analisado, que, por sua vez, foi composto pelos estudantes de uma escola de tempo integral localizada em Campo Grande (MS). Assim, não se pode afirmar que, para outras atividades relacionadas à Astronomia e desenvolvidas em outros 
grupos de análise, serão encontrados os mesmos aspectos motivacionais citados e a mesma conclusão aqui apresentada, pois serão públicos e regiões distintas. Contudo, este estudo apontou caminhos que podem ser seguidos em pesquisas futuras em que possa se desejar encontrar indícios de aspectos motivacionais em indivíduos participantes de uma atividade desenvolvida em um ambiente escolar ou não escolar de ensino.

\section{Referências}

ALVES, M. T. S.; JAFELICE, L. C. Tópicos Astronômicos no Ensino Médio em Natal (RN): Características e Discussões. In: REUNIÃO ANUAL DA SAB, 2005, Águas de Lindóia, SP. Anais... v. 25, p. 79-79, 2005.

ALVES, M. T. S.; ZANETIC, J. O ensino não formal da astronomia: Um estudo preliminar de suas ações e implicações. In: ENCONTRO DE PESQUISA EM ENSINO DE FÍSICA, XI, 2008, Curitiba. Anais...

BRASIL. Secretaria de Educação Média e Tecnologia. Parâmetros Curriculares Nacionais: ciências naturais. Brasília. MEC/SEMTEC. 1997.

BRASIL. Parâmetros Curriculares Nacionais para o Ensino Médio. Brasília: Secretaria de Educação Média e Tecnologia, 1999.

BRASIL. Parâmetros Curriculares Nacionais para o Ensino Médio - Ciências da Natureza, Matemática e suas Tecnologias. Brasília: Secretaria de Educação Média e Tecnologia, 2002.

BRASIL. Base Nacional Comum Curricular (BNCC). Educação é a Base. Brasília, MEC/CONSED/UNDIME, 2017.

BRETONES, P. S. Disciplinas introdutórias de Astronomia nos cursos superiores do Brasil. 1999. (Mestrado) - Instituto de Geociências, UNICAMP.

BZUNECK, J. A. A motivação do aluno: aspectos introdutórios. In: BORUCHOVITCH, E.; BZUNECK, A. (Org.). A motivação do aluno: contribuições da psicologia contemporânea. 3.ed. Petrópolis: Vozes, 2004. Cap.1, p. 9-36.

CANHOTA, C. Qual a importância do estudo piloto? In: SILVA, E. E. (Org.). Investigação passo a passo: perguntas e respostas para investigação clínica. Lisboa: APMCG, 2008. p. 6972. 
CAVENAGHI, A. R. A. Uma perspectiva autodeterminada da motivação para aprender língua estrangeira no contexto escolar. Ciências e Cognição, v. 14, n. 2, 2009.

CAVENAGHI, A. R. A.; BZUNECK, J. A. A motivação de alunos adolescentes enquanto desafio na formação do professor. In: CONGRESSO NACIONAL DE EDUCAÇÃO, IX, 2009, Curitiba. Anais...

CORDEIRO, P. M. G. Construção e Validação do Questionário de Motivação Escolar Para a População Portuguesa: Estudos Exploratórios. 2010. Dissertação (Mestrado em Psicologia Pedagógica) - Universidade de Coimbra, Faculdade de Psicologia e de Ciências da Educação, Portugal.

DECI, E. L.; RYAN, R. M. Intrinsic motivation and self-determination in human Behavior. Plenum Press, 1985.

ENGELMANN, E. A motivação de alunos dos cursos de artes de uma universidade pública do norte do Paraná. 2010. Dissertação (Mestrado em Educação) - Centro de Educação, Comunicação e Artes, Departamento de Educação, Universidade Estadual de Londrina.

FLICK, U. Introdução à pesquisa qualitativa. Porto Alegre: Artmode, 2009.

GUIMARÃES, S. E. R.; BORUCHOVITCH, E. O estilo motivacional do professor e a motivação intrínseca dos estudantes: Uma perspectiva da teoria da Autodeterminação. Psicologia: Reflexão e Crítica, v. 17, n. 2, p. 143-150, 2004.

GIL, A. C. Métodos e técnicas de pesquisa social. 6. ed. São Paulo: Atlas S. A, 2008.

ICE, Instituto de corresponsabilidade pela educação. Modelo pedagógico. Recife, 2015.

KANTOR, C. A. A ciência do céu: uma proposta para o ensino médio. 2001. Dissertação (Mestrado) - Departamento de Física Experimental, Instituto de Física, Universidade de São Paulo, São Paulo.

LANGHI, R. Um estudo exploratório para a inserção da Astronomia na formação de professores dos anos iniciais do Ensino Fundamental. 2004. Dissertação (Mestrado em Educação para a Ciência) - Faculdade de Ciências, UNESP, Bauru. 
LANGHI, R. Astronomia nos anos iniciais do ensino fundamental: repensando a formação de professores. 2009. Tese (Doutorado em Educação para a Ciência) - Faculdade de Ciências, UNESP, Bauru.

LANGHI, R.; NARDI, R. Ensino de Astronomia: erros conceituais mais comuns presentes em livros didáticos de ciências. Caderno Brasileiro de Ensino de Física, v. 24, n. 1, p. 87-111, abr. 2007.

LANGHI, R.; NARDI, R. Formação de professores e seus saberes disciplinares em astronomia essencial nos anos iniciais do ensino fundamental. Revista Ensaio, v. 12, n. 2, p. 205-224, 2010.

LANGHI, R.; MARTINS, B. A. Um estudo exploratório sobre os aspectos motivacionais de uma atividade não escolar para o ensino da Astronomia. Caderno Brasileiro de Ensino de Física, v. 35, n. 1, p. 64-80, 2018.

LINHARES, F. R. C.; NASCIMENTO, S. S. Visitas escolares ao observatório astronômico Frei Rosário: Uma análise quantitativa. XII In: ENCONTRO DE PESQUISA EM ENSINO DE FÍSICA, XII, 2010, Águas de Lindóia. Anais...

MARTINS, B. A. Um estudo exploratório sobre os aspectos motivacionais de uma atividade não escolar para o ensino da Astronomia. 2014. Dissertação (Mestrado Profissional em Ensino de Ciências) - Universidade Federal de Mato Grosso do Sul, Campo Grande.

LANGHI, R.; MARTINS, B. A. Um estudo exploratório sobre os aspectos motivacionais de uma atividade não escolar para o ensino da Astronomia. Caderno Brasileiro de Ensino de Física, v. 35, n. 1, p. 64-80, 2018.

MORAES, R. Uma Tempestade de Luz: A compreensão possibilitada pela Análise Textual Discursiva. Revista Ciência e Educação, v. 9, n. 2, p. 191-211, 2003.

MORAES, R.; GALIAZZI, M. C. Análise textual discursiva: processo reconstrutivo de múltiplas faces. Ciências e Educação, v. 12, n. 1, p. 117-128, 2006.

REEVE, J.; DECI, E. L.; RYAN, R. M. Self-determination theory: a dialectical framework for understanding sociocultural influences on student motivation. In: McINERNEY, D. M.; VAN ETTEN, S. (Ed.) Big theories revisited. Greenwich: Information Age Publishing, 2004. Cap. 3, p. 31-60. 
ROSA, P. R. S. Instrumentação para o ensino de ciências. Universidade Federal de Mato Grosso do Sul. Departamento de Física, Campo Grande, 2011. Cap. v. p. 90-101.

RYAN, R. M.; DECI, E. L. Intrinsic and extrinsic motivations: classic definitions and new directions. Contemporary Educational Psychology, n. 25, p. 54-67, 2000.

RYAN, R. M.; DECI, E. L. Overview of self-determination theory: an organismic dialectical perspective. In: DECI, E. L.; RYAN, R. M. (Ed.). Handbook of self-determination research. Rochester: University of Rochester Press, 2002. Cap. 1, p. 3-33.

\section{Apêndice I}

\section{Prezado aluno}

Este é um questionário contendo nove questões, cujo objetivo é verificar aspectos relacionados à sua motivação frente à eletiva de Astronomia desenvolvida ao longo desse semestre. Esse estudo fará parte de um artigo que será escrito por mim e orientado por minha professora da Universidade Federal de Mato Grosso do Sul (UFMS). Peço que você seja absolutamente sincero em suas respostas.

As suas respostas serão conhecidas apenas por mim e por minha professora. Não é necessário se identificar no questionário em questão.

Desde já agradeço a sua colaboração,

Prof. Me. Bruno de Andrade Martins

Prof. Dra. Maria Celina Recena

\section{Questionário}

1. Você participou dessa eletiva por vontade própria ou alguém externo (familiares, amigos, etc.) pediu a você para participar?

2. Comente e explique sobre o que o motivou a participar dessa eletiva?

3. Comente e explique como foi a sua interação com o professor da eletiva, com os monitores da casa da ciência da UFMS (caso participou dessa atividade) e os colegas de classe durante as atividades desenvolvidas.

4. Dentre todos os temas abordados durante a eletiva, qual ou quais lhe agradaram mais? Justifique.

5. Qual ou quais outros temas você gostaria de estudar em outras atividades e/ou aulas relacionados à Astronomia? 
6. Após a sua participação nessa eletiva, comente e explique se você se sentiu interessado em participar de outras atividades relacionadas ao estudo da Astronomia.

7. Comente e explique se, após a realização dessa eletiva você se sente capaz de buscar mais conhecimentos sobre os temas abordados.

8. Comente e explique se, durante toda a eletiva você se sentiu gratificado ao realizá-la.

9. Comente e explique se, para você os locais onde as atividades foram realizadas foi adequado. 